\title{
EFFECTING FACTORS OF KNOWLEDGE INTEGRATION THROUGH SOCIAL MEDIA IN SMALL MEDIUM ENTERPRISES ENVIRONMENT
}

Nur Ilyana Ismarau Tajuddin

Faculty Computer Science and Information Technology, University Putra, (Malaysia) E-mail: ilyanaismarau90@gmail.com

Rusli Abdulllah

Faculty Computer Science and Information Technology, University Putra, (Malaysia) E-mail: rusli@upm.edu.my

Marzanah A. Jabar

Faculty Computer Science and Information Technology, University Putra, (Malaysia) E-mail: $\underline{\text { marzanah@upm.edu.my }}$

Yusmadi Yah Jusoh

Faculty Computer Science and Information Technology, University Putra, (Malaysia) E-mail:yusmadi@upm.edu.my 


\section{ABSTRACT}

Knowledge Integration (KI) has been significant concern in analyzing the organization performance. KI also has been challenged by the emergence and continued development technologies that have made new sources of information and knowledge available to Small Medium Enterprises (SMEs). Social media are widely adopted by organizations to enhance the effectiveness of KI practices. The purpose of this study to investigate the factors that influence of KI through social media. Based on the 11 selected papers, this review has established 12 factors that may influence of knowledge integration through social media. Hence, this research contribute to the practice and research of KI and social media and its effectiveness towards the organizational performance.

\section{KEYWORDS}

Knowledge Integration, Social Media, Small Medium Enterprise, Systematic Literature Review.

\section{INTRODUCTION}

In the new age, knowledge has been recognized as one of most valuable assets which developed in organization. Knowledge is related to activities and process flow in and between the organizations. Knowledge integration is solitary of the most essential approaches of knowledge applications to attain sustainable competitive advantages and business value [1]. Only the organization has the capabilities of integrating the inside and outside resources to innovate faster, would be able to succeed under the ultra-competitive environment [2]. From the time when knowledge is continually changing and depreciating, organizations cannot possess all the required knowledge by themselves. The key is to utilize expertise that is spread within the enterprise by integrating knowledge [1]. KI is required in many situations where coherent combining of disparate sources and levels of information for some enterprise is necessary [3]. Technological cooperation among firms is important because a large part of the knowledge needed in innovation processes is tacit, and can be transferred through social media interactions [4]. According to [5] the effective adoption of technologies in companies is much depending on technology characteristics, project and organizational characteristics, user and social characteristics, and task characteristics. However, in reality, these factors are much neglected by organizations, especially among small companies. Social media tools have ability to integrate all information and knowledge that can be obtained [6]. Even though reports suggest the social media tools enhance the development of SMEs, there is still little empirical evidence on their adoption and usage from the category of firms [7] especially in the KI [8].

This study aims to investigate the factors that influencing of KI and Social Media. The findings will be able to assist the SMEs manager to adapt Social Media for integrating knowledge. The following section presents the review of the methodology. Subsequently, followed by discussion section in which focused on influencing factors of KI. The final section concludes the current study by revealing the research contribution and proposing for further research possibility.

\section{REVIEW METHODOLOGY}

According to Okoli et al. [9], the SLR processes contains of three stages namely: planning, executing and reporting stage as show in Figure 1. The following sub sections will discuss the processes in details. 


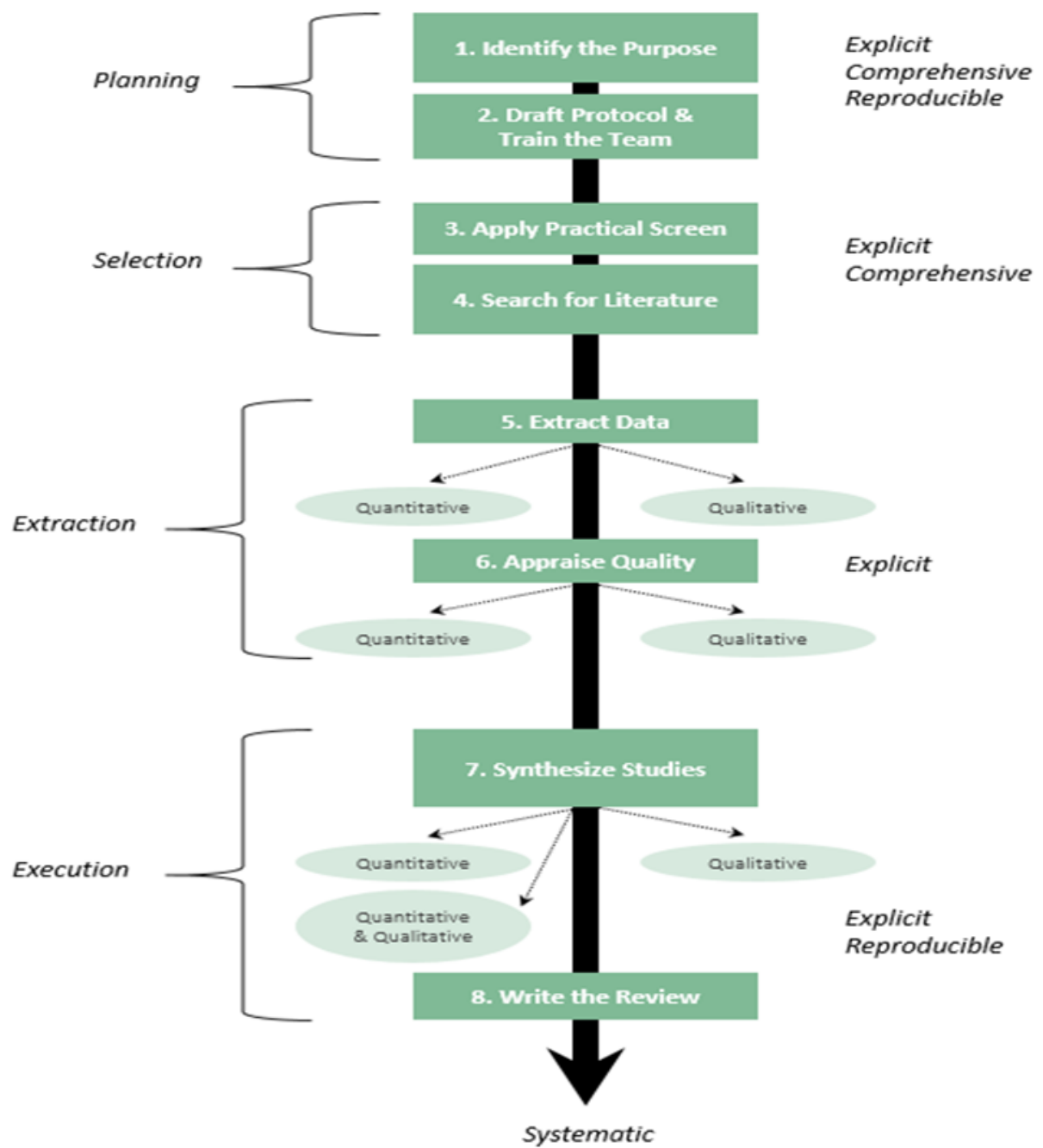

Figure 1. SLR process (Source: Okoli, 2010[9]).

\subsection{Planning Stage}

The planning stage activities include identifying specific research context, defining reviewing protocols, and constructing of research questions. The research question (RQ) is 'What are the factors that influence the KI through social media'.

\subsection{Executing Stage}

A literature search was conducted from December 2010 to September 2017 using three leading electronic journal databases. The databases are ACM, IEE, Science Direct and Scopus. The search was limited to peer-reviewed, English-language journal papers published between 1996 and 2016. Search result for SCOPUS, Science Direct, IEEE and ACM are summarize in Table 1. The search analyst titles and abstracts for a number of related keywords and phrases: "knowledge integration", "knowledge combination", "knowledge mapping", "knowledge collaboration", "social media", "technology", "social network", "organization", "Small Medium Enterprises" etc. When searching in the databases, therefore, we use three couples of combinative keywords: (knowledge AND integration), (knowledge AND combination) and (knowledge AND collaboration) etc. The result is shown as Table 2 .

Certain criteria have been set in choosing the articles. The article was only included if it met the following criteria. Firstly, its focus was primarily on KI/ Social media. Secondly, 
the area investigated included SMEs environment. Finally if only the article are discussed factors effect on KI through Social Media. The current research focus merely in peerreviewed primary studies published in academic journals were included, resulting in the exclusion of literature reviews, conceptual articles, conference proceedings. The articles which full filled the above-mentioned three criteria were scanned by the authors for additional studies that met the inclusion criteria for the review. In this stage, the duplicated articles were removed. Further, the articles were screened for relevance, primarily based on the title and abstract.

Table 1. Search Result based on Year.

\begin{tabular}{|l|l|l|l|l|}
\hline Year Search & Scopus & $\begin{array}{l}\text { Science } \\
\text { Direct }\end{array}$ & IEEE & ACM \\
\hline $\mathbf{2 0 1 7}$ & 70 & 156 & 300 & 6 \\
\hline $\mathbf{2 0 1 6}$ & 98 & 267 & 354 & 4 \\
\hline $\mathbf{2 0 1 5}$ & 125 & 273 & 341 & 4 \\
\hline $\mathbf{2 0 1 4}$ & 188 & 200 & 484 & 2 \\
\hline $\mathbf{2 0 1 3}$ & 183 & 182 & 426 & 5 \\
\hline $\mathbf{2 0 1 2}$ & 190 & 166 & 458 & 1 \\
\hline $\mathbf{2 0 1 1}$ & 192 & 140 & 500 & 1 \\
\hline $\mathbf{2 0 1 0}$ & 122 & 272 & 340 & 4 \\
\hline
\end{tabular}

Table 2. Search Result based on Keyword.

\begin{tabular}{|l|c|c|c|}
\hline & $\begin{array}{c}\text { knowledge } \\
\text { AND } \\
\text { integration }\end{array}$ & $\begin{array}{c}\text { knowledge } \\
\text { AND } \\
\text { combination }\end{array}$ & $\begin{array}{c}\text { knowledge } \\
\text { AND } \\
\text { collaboration }\end{array}$ \\
\hline Scopus & 7 & 13 & 35 \\
\hline $\begin{array}{l}\text { Science } \\
\text { Direct }\end{array}$ & 90 & 56 & 130 \\
\hline IEEE & 2200 & 1745 & 1955 \\
\hline ACM & 3 & 3 & 6 \\
\hline
\end{tabular}

The selected papers were analyzed and synthesized before findings and results be discussed in the following section. This was followed by the quality assessment screening. The quality assessment was formulated to evaluate the completeness of papers and advantageous for data extraction [10]. These four questions (Q1-Q4) are presented in Table 3. Each question has only three answer options: Yes $=1$; Partially $=0.5$; and $\mathrm{No}=0$.

Table 3. Quality Assessment Criteria.

\begin{tabular}{|l|l|l|}
\hline No. & Item & Answer \\
\hline Q1 & $\begin{array}{l}\text { Is there a clear description of the aims and objectives of the } \\
\text { investigation? }\end{array}$ & Yes/No \\
\hline Q2 & $\begin{array}{l}\text { Is the paper explained the method of analysis pertinent and } \\
\text { adequately? }\end{array}$ & $\begin{array}{l}\text { Yes/No/ } \\
\text { Partially }\end{array}$ \\
\hline Q3 & $\begin{array}{l}\text { Is the paper supported by primary data? } \\
\text { Yes/No }\end{array}$ & Yes/No/Partially \\
\hline Q4 & Is the paper explained the model structure in detail? & \\
\hline
\end{tabular}

\subsection{Reporting Stage}

In reporting stage, the findings and results were discussed in section 3 . 


\section{FINDING AND ANALYSIS}

A total of 259 references that are deemed relevant to this topic. In the next stage, the abstract and brief content of selected paper was evaluated. The 40 relevant papers were then filtered by applying the quality assessment criteria. In the very final round, only 11 papers out of 40 papers $(27.5 \%)$ were accepted for data synthesis of evidence after executing exclusion criteria. The summary of the quality assessment of the 11 papers (A1-A11) considered for this review as show in Table 4.

Table 4. Quality Assessment Result.

\begin{tabular}{|l|l|l|l|l|l|}
\hline ID & Q1 & Q2 & Q3 & Q4 & Total \\
\hline A1 & 1 & 0 & 0 & 1 & 2 \\
\hline A2 & 1 & 1 & 1 & 1 & 4 \\
\hline A3 & 1 & 0.5 & 0 & 1 & 2.5 \\
\hline A4 & 1 & 0.5 & 0 & 1 & 2.5 \\
\hline A5 & 1 & 1 & 1 & 1 & 4 \\
\hline A6 & 1 & 1 & 1 & 1 & 4 \\
\hline A7 & 1 & 1 & 1 & 1 & 4 \\
\hline A8 & 1 & 1 & 1 & 0 & 3 \\
\hline A9 & 1 & 1 & 1 & 1 & 4 \\
\hline A10 & 1 & 1 & 1 & 1 & 4 \\
\hline A11 & 1 & 1 & 1 & 1 & 4 \\
\hline
\end{tabular}

Table 5 exemplifies the filtering result of the quality assessment of all that paper that was classified as good and very good scores. Among the 11 selected papers, three papers has scored good quality in which consists of 27 percentage and eight papers scored a very good quality scoring with 73 percentages.

Table 5. Quality Scores.

\begin{tabular}{|c|c|c|c|c|c|}
\hline Quality Scale & $\begin{array}{c}\text { Very poor } \\
(<1)\end{array}$ & $\begin{array}{c}\text { Poor } \\
(1-<2)\end{array}$ & $\begin{array}{c}\text { Good } \\
(2-<3)\end{array}$ & $\begin{array}{c}\text { Very good } \\
(3-4)\end{array}$ & Total \\
\hline Number of studies & 0 & 0 & 3 & 8 & 11 \\
\hline Percentage $(\%)$ & 0 & 0 & 27 & 73 & 100 \\
\hline
\end{tabular}

These 11 papers were investigated in the area of Knowledge Integration area is categorized in three types of research analysis includes conceptual, empirical and case study. Remarkably, there were seven publication of empirical studies published from the year 2011 until the year of 2017. Further, followed by three conceptual paper published from 2010-2012 and a case study in 2015. The KI publication trend is presented in Figure 2 and Figure 3. 


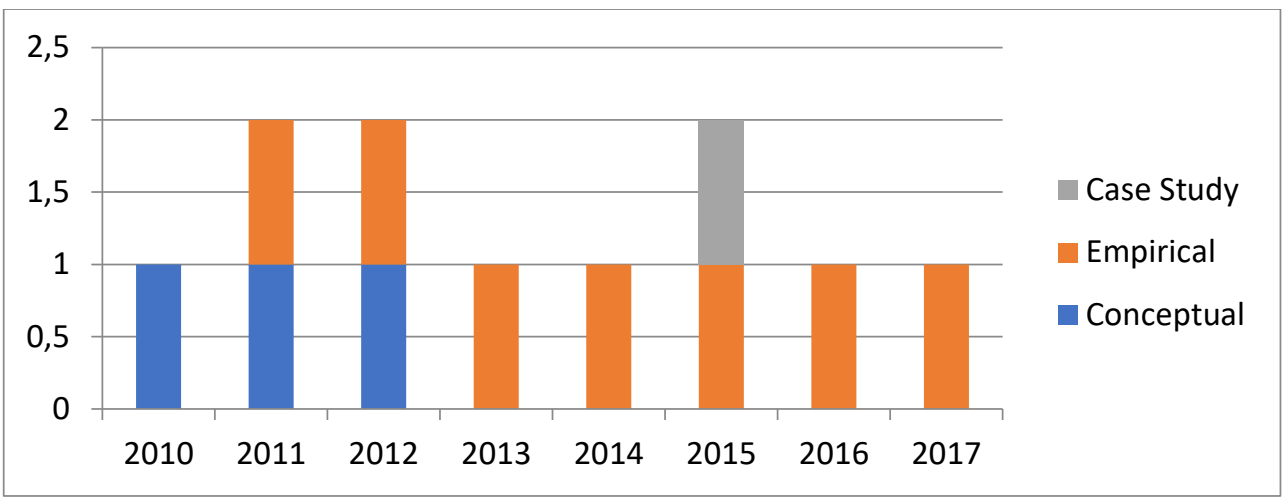

Figure 2. Paper distribution by publication year.

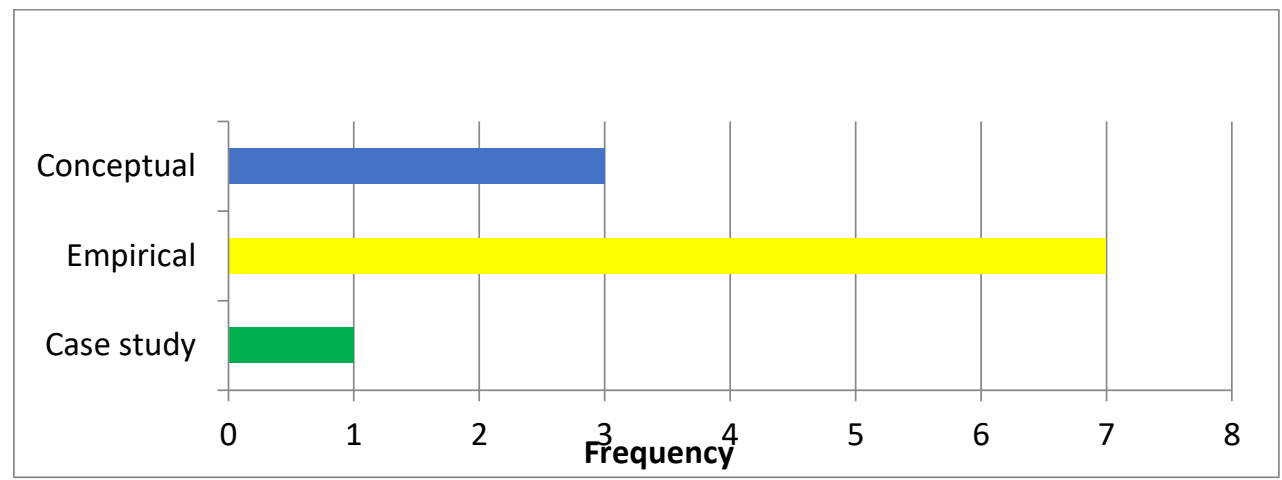

Figure 3. The frequency of research analysis.

Figure 4 displays the KI studies based on domain specific. Nine papers (82\%) are from various organizations only 1 paper $(9 \%)$ from manufacturing sector and healthcare. Table 6 display the summary of the relationship of the influencing factors in KI.

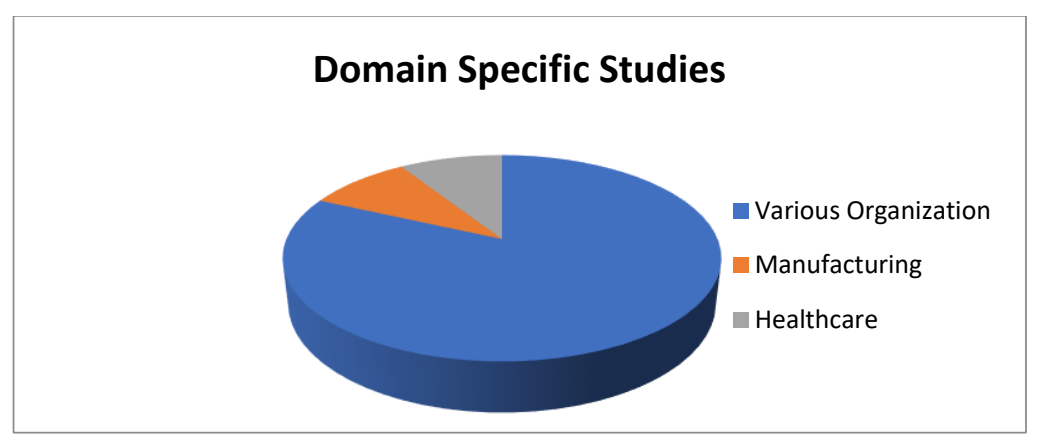

Figure 4. Domain specific studies.

Table 6. Summary of the Relationship of the Influencing Factors in KI.

\begin{tabular}{|l|l|c|c|c|}
\hline ID & $\begin{array}{c}\text { Type of } \\
\text { research }\end{array}$ & Sample size & Domain & Source \\
\hline A1 & Conceptual & N/A & $\begin{array}{c}\text { Various } \\
\text { organization }\end{array}$ & {$[11]$} \\
\hline A2 & Empirical & $\begin{array}{c}\text { Various } \\
\text { organization } \\
\text { manager, senior, CEO }\end{array}$ & $\begin{array}{c}\text { Various } \\
\text { organization }\end{array}$ & {$[12]$} \\
\hline A3 & Conceptual & ABC Co Ltd & $\begin{array}{c}\text { Various } \\
\text { organization }\end{array}$ & {$[14]$} \\
\hline A4 & Conceptual & Multi-vendor & \\
\hline
\end{tabular}




\begin{tabular}{|c|c|c|c|c|}
\hline A5 & Empirical & $\begin{array}{l}157 \text { full time professional } \\
\text { from variety industry }\end{array}$ & $\begin{array}{c}\text { Various } \\
\text { organization }\end{array}$ & [15] \\
\hline A6 & Empirical & $\begin{array}{l}262 \text { Chinese working } \\
\text { professional }\end{array}$ & $\begin{array}{c}\text { Various } \\
\text { organization }\end{array}$ & {$[8]$} \\
\hline A7 & Empirical & $\begin{array}{c}182 \text { Taiwan Manufacturing } \\
\text { Firm }\end{array}$ & Manufacturing & [16] \\
\hline A8 & Case Study & ABC Company & $\begin{array}{c}\text { Various } \\
\text { organization }\end{array}$ & [17] \\
\hline A9 & Empirical & 265 high technology firm & $\begin{array}{c}\text { Various } \\
\text { organization }\end{array}$ & [18] \\
\hline A10 & Empirical & 317 clinic staff & Healthcare & [19] \\
\hline Al1 1 & Empirical & 114 worker from China & $\begin{array}{c}\text { Various } \\
\text { organization }\end{array}$ & [20] \\
\hline
\end{tabular}

Grounded on prior research as mention in Table 6, number of 12 factors have been emerged as factors that influences the KI as illustrated in Table 7.

Table 7. Influencing Factors of KI Studies.

\begin{tabular}{|c|c|c|}
\hline No & Factors & Articles \\
\hline 1 & Organizational Learning & A2, A4 \\
\hline 2 & Social Capital & A6, A4 \\
\hline 3 & Social network & A5, A8,A1,A3 \\
\hline 4 & IT Capability & A2 \\
\hline 5 & Media interactive & A8 \\
\hline 6 & Competitive industry & A9 \\
\hline 7 & Market turbulence & A9 \\
\hline 8 & Technology turbulence & A9 \\
\hline 9 & Knowledge integration mechanism & A7, A9, A4 \\
\hline 10 & Integrative Capability & A1 \\
\hline 11 & Transactive Memory System & A1, A5, A8, A3, A11 \\
\hline 12 & Teamwork & A10 \\
\hline
\end{tabular}

Figure 5 presents the frequency of influencing factors of KI studies. KI factors comprises of Organizational Learning (2 papers), Social Capital (2 papers), Social Network (4 papers), IT Capability (1 paper), Media Interactive (1 paper), Competitive Industry (1 paper), Market Turbulence (1 paper), Technology Turbulence (1 paper), Knowledge Integration Mechanism (3 papers), integrative Capability (1 paper), Transactive Memory System ( 5 papers) and Teamwork (1 paper). Based on Table 5 and Figure 4 , the detail of each factors will be discuss in the discussion section. 


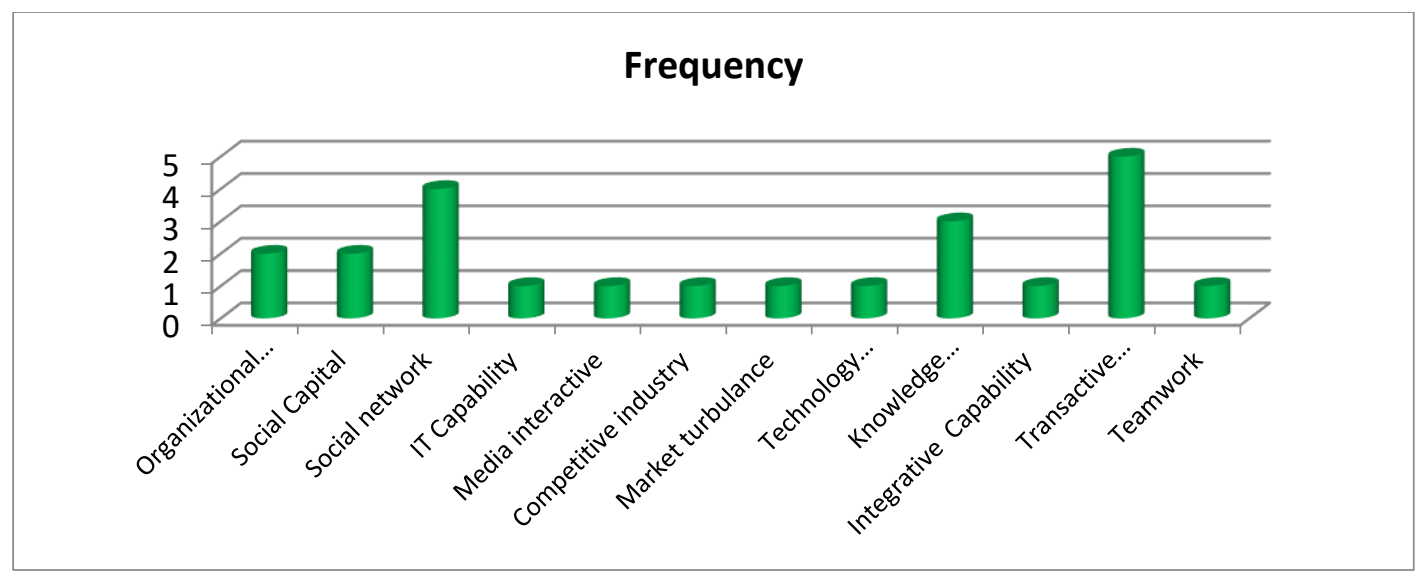

Figure 5. Frequency of influence factors of KI.

\section{DISCUSSION}

Based on prior research, there are 12 factors that are effecting of KI:

\subsection{Organizational Learning}

Organizational learning refers as an organization's developing new thinking and creating new knowledge to enhance prevailing resources [21]. On the other hand, organizational learning as gaining knowledge, skill, value, belief in improving growth and developing the organization. Organizational learning have effect to KI to advance the organization performances $[12,14]$. Thus, organizational learning is significant considered factor to improve SMEs performances.

\subsection{Social Capital}

Social capital refers as the networks of relationships among people who live and work in a particular society, enabling that society to function effectively. Social capital inheres in the relationships between actors within the social network [22]. The dimensions consist in social capital is structural [14] relational and cognitive [8]. Social capital is the significant effect to be considered for organization performances.

\subsection{Social Network}

The social network is the level of connectivity and access among individuals in organization to enable communication, dialogue and interaction between organizations to integrate knowledge [23]. Social network do has effect on the KI [11, 13, 15, and 17]. Social network have been developed and have been applied to knowledge processing. Thus, social network is substantial to be considered in knowledge integration.

\subsection{IT Capability}

IT capability refers as the ability to effectively manage the hardware and software that has different type and levels of knowledge [12]. IT capability allows user to communicate with each other, facilitate knowledge acquisition and integration, easily reach expert in specialized areas, and foster boundary straddling activities [24]. Thus, IT Capability is significant to consider in knowledge integration in SMEs.

\subsection{Media Interactive}

In other hand, by amending a form and the contents of it the user are able to create the mediating affect of the environment on the moment, in which define the media interactive. Media interactive include five crucial elements. The components are: (a) 
amount of acceptable input, (b) the number and type of characters that are able to be applied changes, (c) the distance of ability to receive message; the capability to integrate, build, and reconfigure inner and outer knowledge to response to environmental change [28]. Media interactivity has an important role in social media. Prior research [17] has clearly found media interactivity to have a positive relationship to knowledge integration in the organization.

\subsection{Competitive Industry}

Competitive industry is the degree of competition that a firm faces in the respective industry [26]. Competitive industry has relationship to KI in organization [18].

\subsection{Market Turbulence}

Market turbulence is the rate at which customer composition and customer preferences change. Market turbulence has relationship to KI in the organization [18]. Although there are few studies on the relationship between market turbulence and KI has shown that market turbulence positively influences. Thus, market turbulence is significant consider effect to KI.

\subsection{Technology Turbulence}

Technology turbulence is the rate of change in technologies involved in the development of new product. In order to enhancing organization performance, an organization's willingness to explore new technologies for product or service innovation is likely to depend on the opportunities or threats arising from environmental changes Technology turbulence has a relationship to KI in the organization [18]. Although there are few studies on the relationship between technology turbulence and KI has shown that technology turbulence positively influences. Thus, technology turbulence is significant consider effect to knowledge.

\subsection{Knowledge Integration Mechanism (KIM)}

Knowledge Integration Mechanism (KIM) are structures and processes for integrating the different types of knowledge among the different functional unit in the organization [27]. KIM consist of three perspectives, namely systems and procedural mechanisms, interactive mechanisms and boundary-crossing mechanisms. Prior studies [14, 16, and 18] suggested KIM has effect to KI in the organization performances and new product development.

\subsection{Integrative Capability}

Integrative capability refers to a firm's ability to acquire, combine and deploy resources. Prior research on dynamic capabilities and combinative capabilities presents insight into the relationship between organization's integrative capability and knowledge integration. Dynamic capability refers to an ability to integrate, build, and reconfigure internal and external knowledge to respond to environmental change [28]. Integrative capability, including ability to enter and gain external new knowledge. The capability to recognize internal knowledge are in position to achieve a total new positive relation to knowledge integration [17].

\subsection{Transactive Memory System (TMS)}

Transactive Memory System (TMS) refers as cooperative division of labor for remembering, learning, and communicating relevant knowledge [29]. TMS is the 
mechanisms that can help team's member recognize other's expertise. Team members can rely on each other's expertise to complete a task based on specific domain. TMS consists of three construct which are specialization, credibility and coordination. TMS also has an important role in social media. TMS is posited to have positive relations to KI $[12,13,15,17$, and 20]. Therefore, TMS is acknowledging as key factor of KI through social media.

\subsection{Teamwork}

The team are viewable as a knowledge integrating mechanisms, individual knowledge can be shared and mobilized in the team [30]. The empirical study has undoubtedly found that the effective teamwork are required in KI [19] in order to emergent process of rich exchanges and joint problem solving to integrate and apply knowledge and expertise to the task at hand in a coordinated manner [31].

\section{CONCLUSION IN FUTURE WORK}

This study provided insight on influence factors of KI and social media, which important determinant of SMEs performances. A total ten relevant papers were thoroughly reviewed and analyze. The review process has identified and categorized the influenced factors of KI. There are twelve factors which have been identified to influence of KI. These factors includes: Organizational Learning, Social Capital, Social Network, IT Capability, Media Interactive, Competitive Industry, Market Turbulence, Technology Turbulence, Knowledge Integration Mechanism, integrative Capability, Transactive Memory System and Teamwork. The factors of KI and social media necessity to authenticate and validate through further research in order to gain better insights of the current research.

\section{REFERENCES}

[1] Grant, R.M. Toward a knowledge-based theory of the firm. Strategic Management Journal, 17 (S), 109- 122 (1996).

[2] Gao Wei, Wang Hengshan, N.-W. Bin. Knowledge Integration and Its Impact.In International Conference on Managment Science \& Engineering. 1517-1523 (2007).

[3] Hustad, E. A Conceptual Framework for Knowledge Integration in Distributed Networks of practice. Proceedings of the 40th Hawaii International Conference on System Sciences - 2007, 1-10 (2007).

[4] Raban, Y. 12 Supporting Knowledge Integration at SMEs - Policies Profiles of KI Support Measures for SMEs. (J. K. Antonie Jetter, Ed.). Physica Verlag - A Springer Company (2008).

[5] Petter, S., DeLone, W., \& McLean, E. R. Information Systems Success: The Quest for the Independent Variables. Journal of Management Information Systems, 29(4), 7-61 (2013).

[6] Fung, C. K., \& Hung, P. C. Information and knowledge management in online rich presence services. Information Systems Frontiers, 1-3 (2013).

[7] Dixon, Brian E. Towards E-Government 2.0: An Assessment of Where EGovernment 2.0 Is and Where It Is Headed. Public Administration \& Management, 15(2), 418-454 (2010). 
[8] Cao, X., Guo, X., Liu, H., \& Gu, J. The role of social media in supporting knowledge integration: A social capital analysis. Information Systems Frontiers, 1-12 (2013).

[9] Okoli, Chitu, and Kira Schabram. "A guide to conducting a systematic literature review of information systems research." (2010).

[10] Adrian, R. Abdullah, R. Atan and Y. Y. Jusoh, "Factors influencing to the implementation success of big data analytics: A systematic literature review," 2017 International Conference on Research and Innovation in Information Systems (ICRIIS), Langkawi, 2017, pp. 1-6.

[11] Hong, D. C., \& Liang, S. Media Characteristics and Social Networks-enabled Knowledge Integration in Cooperative Work.Procedia Computer Science, 60, 246-255 (2015).

[12] Kim, Y. J., Song, S., Sambamurthy, V., \& Lee, Y. L. Entrepreneurship, knowledge integration capability, and firm performance: An empirical study. Information Systems Frontiers, 14, 1047-1060 (2011).

[13] Ling, Hong, Dao Cheng Hong, and Cheng Hong Zhang. "Research on tacit knowledge integration: a synthesis of social ties and TMS." Knowledge Management Research \& Practice 9.3 :256-262 (2011).

[14] Jin, Xiaowei, and Julia Kotlarsky. "A Conceptual Framework of Knowledge Integration in Multisourcing Arrangements." (2012). 33th International Conference on Information System, Orlando. 2012.

[15] Zhang, C.H., Hong, D., Ling, H. A Study On The Mechanism Of Tacit Knowledge Integration: The Role Of Social Ties And Transactive Memory Systems. International Journal of Innovative Computing, Information and Control, 8(8), 5847-5857 (2012).

[16] Tsai, Kuen-Hung, and Teresa Tiaojung Hsu. "Cross-Functional collaboration, competitive intensity, knowledge integration mechanisms, and new product performance: A mediated moderation model." Industrial Marketing Management 43.2 : 293-303 (2014).

[17] Hong, D. C., \& Liang, S. Media Characteristics and Social Networks-enabled Knowledge Integration in Cooperative Work. Procedia Computer Science, 60, 246255 (2015).

[18] Tsai, K.-H., Liao, Y.-C., \& Hsu, T. T. Does the use of knowledge integration mechanisms enhance product innovativeness? Industrial Marketing Management, 46, 214-223 (2015).

[19] Korner, M., Corinna, L., Becker, S., Lars, R., Christian, M., \& Linda, Z. Knowledge Integration, teamwork and performance in health care. Journal of Health Organization and Management, 30(2), 227-243 (2016).

[20] Hong, D., \& Zhang, L. ScienceDirect Does Transactive Memory Systems Promote Knowledge Integration Directly? Procedia Computer Science, 112, 896-905 (2017).

[21] Kessel, F. G. A. Van. No Creative Person is an Island: Organisational Culture , Acedemic Project Based Creativity, Mediating role of Intraogranisational Social Ties. SAJEMS Special Issues, 17(17), 46-69 (2014).

[22] Coleman, J. S. Social capital in the creation of human capital. The American Journal of Sociology, 94,95-120 (1988). 
[23] Chow, W. S., \& Chan, L. S. Social network, social trust and shared goals in organizational knowledge sharing. Information \& Management, 45(7), 458-465 (2008).

[24] Dewett, T., \& Jones, G. The role of information technology in the organization: a review, model, and assessment. Journal of Management, 27(3), 313-346 (2001).

[25] Lombard, Matthew, Jennifer Snyder-Duch, and Cheryl Cam- panella Bracken. 2002. "Content Analysis in Mass Communication: Assessment and Reporting of Intercoder Reliability." Human Communication Research 28 (4): 587- 604.

[26] Cui, A. S., Griffith, D. A., \& Cavusgil, S. T. The influence of competitive intensity and market dynamismon knowledgemanagement capabilities of multinational corporation subsidiaries. Journal of International Marketing, 13(3), 32-53 (2005).

[27] De Luca, L. M., \& Atuahene-Gima, K. Market knowledge dimensions and crossfunctional collaboration: Examining the different routes to product innovation performance. Journal of Marketing, 71(1), 95-112 (2007).

[28] Zollo, M., \& Winter, S. G. Deliberate learning and the evolution of dynamic capabilities. Organization Science, 13(3), 339-351 (2002).

[29] Hollinshed A. B., "Communication, learning, and retrieval in transactive memory systems", Journal of Experimental Social Psychology, 34 (5) .423-442 (2002).

[30] Erhardt, N. Is it all about teamwork? Understanding processes in team-based knowledge work. Management Learning, 42(1), 87-112 (2011).

[31] Alavi, Maryam, and Amrit Tiwana. "Knowledge integration in virtual teams: The potential role of KMS." Journal of the Association for Information Science and Technology 53.12: 1029-1037 (2002). 